\title{
Prognostic Factors Associated with Ocriplasmin Efficacy for the Treatment of Symptomatic Vitreomacular Adhesion and Full-thickness Macular Hole: Analysis from Four Studies
}

\author{
Brian C. Joondeph, MD, MPS ${ }^{1}$; Paul Willems, MD $^{2}$; Thomas Raber, $\mathrm{PhD}^{2}$; Luc Duchateau, $\mathrm{PhD}^{3}$ \\ Joseph Markoff, PhD, MD ${ }^{4,5}$ \\ ${ }^{1}$ Colorado Retina Associates, Denver, Colorado, USA \\ ${ }^{2}$ Oxurion, Leuven, Belgium \\ ${ }^{3}$ Biometrics Research Group, Ghent University, Gent, Belgium \\ ${ }^{4}$ Wills Eye Hospital, Philadelphia, Pennsylvania, USA \\ ${ }^{5}$ Thomas Jefferson Medical College, Philadelphia, Pennsylvania, USA \\ ORCID: \\ Brian C. Joondeph: https://orcid.org/0000-0001-8781-4370
}

\section{Abstract}

Purpose: To assess the effect of patient baseline characteristics on the efficacy of ocriplasmin treatment for symptomatic vitreomacular adhesion (VMA) with full-thickness macular hole (FTMH) from phase $3 / 4$ studies.

Methods: Patients with symptomatic VMA and FTMH at baseline and receiving ocriplasmin treatment $125 \mu \mathrm{g}$ were pooled from the MIVI-TRUST, OASIS, and ORBIT studies. Multivariable logistic regression analysis was used to evaluate whether patient baseline characteristics were predictors of having VMA resolution by Day 28 and FTMH closure by Month 6.

Results: Two hundred and seventy-four patients receiving ocriplasmin treatment were assessed. Overall, 22.6\% (62/274) of the patients experienced both VMA resolution by Day 28 and non-surgical FTMH closure by Month 6 . Patients with FTMH $\leq 250 \mu \mathrm{m}$ at baseline had a significantly higher success rate compared to those with FTMH $>400$ $\mu \mathrm{m}(29.9 \%$ [41/137] vs 2.2\% [1/48]; $P=0.009)$. In patients with VMA resolution by Day 28 , both small FTMH size $(P=0.001)$ and FTMH width at RPE $(P=0.012)$ were significantly associated with a higher FTMH closure rate. Patients with VMA resolution had higher rates of FTMH closure. Previously identified baseline predictive factors, including age, lens status, or presence of epiretinal membrane (ERM) were not found to be predictive of both VMA release and FTMH closure.

Conclusion: The analysis revealed that FMTH $\leq 250 \mu \mathrm{m}$ was the only factor predictive for achieving both pharmacological VMA resolution by Day 28 and nonsurgical FTMH closure by Month 6; neither lens status or presence of ERM, previously identified baseline characteristics favoring VMA resolution, showed statistically significant predictive power for both outcomes.

Keywords: Ocriplasmin; Full-thickness Macular Hole; Vitreomacular Adhesion; Symptomatic Vitreomacular Adhesion; Vitreomacular Traction; Vitreoretinal Interface 


\section{INTRODUCTION}

Aging of the eye often leads to separation between the posterior vitreous cortex and the internal limiting membrane, known as posterior vitreous detachment (PVD). ${ }^{[1,2]}$ This process may be affected by vitreomacular adhesion (VMA), or adherence of the vitreous cortex to the macula after partial detachment. ${ }^{[3-5]}$ Symptomatic VMA (also referred to as vitreomacular traction) can occur if mechanical forces are large enough to cause anatomical changes to the macula. ${ }^{[6,7]}$ Effects resulting from symptomatic VMA may also lead to the development of a full-thickness macular hole $(\mathrm{FTMH}){ }^{[4]}$ The occurrence of VMA and FTMH can lead to visual disturbances such as decreased visual acuity, photopsia, metamorphopsia, scotomas, and may result in irreversible vision loss if left untreated. ${ }^{33,4,8-12]}$

Treatment options for symptomatic VMA include watchful waiting, vitrectomy, pneumatic vitreolysis, and pharmacological vitreolysis with ocriplasmin. Ocriplasmin was approved in the US in 2012 and the EU in 2013 based on the results of two pivotal phase 3 clinical trials (MIVI-TRUST) that established its efficacy and safety in patients with symptomatic VMA with or without an associated FTMH $\leq 400 \mu \mathrm{m} \cdot{ }^{[13]}$ An earlier post hoc analysis of the pivotal trials suggested that the efficacy of ocriplasmin may be increased by patient baseline characteristics, including younger age, phakic lens status, focal VMA, absence of epiretinal membrane (ERM), and presence of FTMH. ${ }^{[14]}$ Subsequently, both prospective and retrospective studies ranging from 5 to 74 eyes were undertaken that assessed the effect of these baseline factors with respect to VMA release. ${ }^{[13,15-32]}$ VMA release rates in these studies ranged from $0 \%$ to $71 \%$, with 14 of 18 studies showing higher efficacy than the pivotal phase 3 trial rate of $26.5 \%$ VMA release at Day $28 .{ }^{[13]} \mathrm{A}$ meta-analysis of these studies, which also included

Correspondence to:

Brian C. Joondeph, MD, MPS. 8101 E. Lowry Blvd, Suite 210 Denver, Colorado 80230 (303) 261-1600, USA.

E-mail: bjoondeph@retinacolorado.com

Received: 02-06-2020 Accepted: 23-10-2020

Access this article online

Website: https://knepublishing.com/index.php/JOVR

DOI: 10.18502/jovr.v16i1.8250 the phase 3 pivotal trials, confirmed that focal VMA, absence of ERM, phakic lens status, and younger age were all positive predictive factors for VMA release. ${ }^{[33]}$

The rate of FTMH closure for ocriplasmin-treated eyes was $40.6 \%$ in the pivotal clinical trials and $30.0 \%$ in the OASIS study. ${ }^{[13,34]}$ Although analysis of baseline predictive factors has resulted in realworld rates of VMA release higher than those in the pivotal phase 3 trials, multiple real-world studies have reported FTMH closure rates lower than those observed in these studies, suggesting that the predictive factors for FTMH closure may not be the same as those for VMA release and are not as well understood. ${ }^{[24,28,35]}$ For instance, the absence of ERM did not have a clear association with FTMH closure in the MIVI-TRUST trials. ${ }^{[36]}$ In addition, the predictive value of successful VMA release on FTMH closure remains unclear; there was no clear association between VMA release and FTMH closure in the MIVI-TRUST trials, ${ }^{[36]}$ although a recent study showed a strong association between VMA release and FTMH closure. ${ }^{[37]}$

Although the baseline factors associated with VMA resolution and FTMH closure have been investigated individually, to our knowledge no study has assessed factors that may predict both VMA resolution and FTMH closure following ocriplasmin treatment. The current study aimed at assessing the baseline factors that may be predictive of both VMA release together with FTMH closure in patients treated with ocriplasmin in the completed phase 3/4 studies.

\section{METHODS}

\section{Study Population}

Patients diagnosed with both symptomatic VMA and FTMH at baseline and receiving treatment of ocriplasmin $125 \mu \mathrm{g}$ were pooled from the MIVITRUST, OASIS, and ORBIT studies. MIVI-TRUST

This is an open access journal, and articles are distributed under the terms of the Creative Commons Attribution-NonCommercial-ShareAlike 4.0 License, which allows others to remix, tweak, and build upon the work non-commercially, as long as appropriate credit is given and the new creations are licensed under the identical terms.

How to cite this article: Joondeph BC, Willems P, Raber T, Duchateau L, Markoff J. Prognostic Factors Associated with Ocriplasmin Efficacy for the Treatment of Symptomatic Vitreomacular Adhesion and Full-thickness Macular Hole: Analysis from Four Studies. J Ophthalmic Vis Res 2021;16:4255. 
(NCT00781859 and NCT00798317) consisted of two phase 3, prospective, randomized, multicenter, double-blind, placebo-controlled clinical trials (TG-MV-006 and TG-MV-007) in which patients were randomized to receive a single intravitreal ocriplasmin $(125 \mu \mathrm{g})$ or placebo injection. ${ }^{[13]}$ OASIS (NCT01429441) was a phase 3b, randomized, multicenter, double-masked, sham-controlled clinical trial in which patients were randomized to receive a single intravitreal ocriplasmin 125 $\mu \mathrm{g}$ injection or sham treatment. ${ }^{[34]}$ ORBIT (NCT02079883) was a phase 4, prospective, multicenter, observational study to assess a single intravitreal ocriplasmin injection of $125 \mu \mathrm{g}$. $^{[38]}$ Full details of individual study designs, treatment plans, and adherence to ethics practices have been published elsewhere. ${ }^{[13,34,38]}$

\section{Baseline Demographics and Patient Characteristics}

The following baseline demographic and ocular characteristics were evaluated in the study population based on availability across datasets: age ( $<65$ years, $\geq 65$ years), lens status (phakic, pseudophakic), ERM status (present, absent), ellipsoid zone (EZ) status (normal, abnormal), subretinal fluid (SRF) status (present, absent), BCVA $(<65,65-75,>75$ ETDRS letters), diameter of VMA $(\leq 1500 \mu \mathrm{m},>1500 \mu \mathrm{m})$, width of FTMH $(\leq 250,>250-400,>400 \mu \mathrm{m})$, and width of FTMH at the retinal pigment epithelium (RPE) $(\leq 600 \mu \mathrm{m}$, $>600 \mu \mathrm{m}$ ) (Supporting Information Table S1).

For the MIVI-TRUST trials, the presence and size of VMA and FTMH status at baseline were assessed by a central reading center (CRC), using mandatory time-domain optical coherence tomography (TD-OCT) as required per protocol; additional spectral-domain (SD)-OCT readings if available were only used as supportive information for evaluation of individual cases. ${ }^{[13]}$ FTMH was defined as a macular hole with bare/exposed RPE, with the largest of the minimum hole width measurements considered as the hole width based on macular thickness map (MTM) or fast macular thickness map (FMTM) scans. In the more recent OASIS study, the presence and size of VMA and FTMH status at baseline were assessed by a CRC using SD-OCT. ${ }^{[34]}$ FTMH diameter was defined as the largest of the minimum hole width measurement. Although patients were enrolled in the OASIS trial based on favorable baseline characteristics, ${ }^{[14]}$ determination of ocular characteristics differed between investigator and CRC assessment, resulting in inclusion of some patients despite their CRC assessment meeting exclusion criteria in retrospect (FTMH $>400 \mu \mathrm{m}$, presence or ERM). ${ }^{[34]}$ In the ORBIT study, the presence of VMA and FTMH was determined by SD-OCT according to the treating physician before enrollment and reviewed independently by a CRC in retrospect. FTMH diameter was defined as the greatest width of the minimum distance between sides of the FTMH measured within the middle two thirds of the retina (not at surface and not at RPE) in any line of the 49-line volume scan. The review of the presence of VMA and FTMH by the CRC was performed post-treatment in all studies and was not used for treatment decisions.

EZ status was evaluated in the central macular region in all studies. SRF assessments were defined in each of the studies. In the MIVI-TRUST trials, SRF was a measure of the fluid beneath retina to other material perpendicular to Bruch's membrane at the foveal center from the retina to the RPE, not including fluid within the retinal layer (cysts) or fluid below the RPE. In the OASIS study, three foveal center point measurements were taken, including SRF, RPE elevation and/or subretinal hyper-reflective material (SHRM) such as choroidal neovascularization, and total retinal thickness. The total retinal thickness measurement included the RPE layer, RPE elevation, any SHRM, any SRF, and the retina at the foveal center. When a value was not reported for SRF or RPE elevation and/or SHRM, it was considered not present or ungradable. In the ORBIT study, SRF was considered present if it was identified in any line scan in the absence of FTMH.

\section{Statistical Analysis}

The integrated database included all patients who presented with symptomatic VMA and FTMH at baseline, were treated with ocriplasmin $125 \mu \mathrm{g}$, and had both a baseline assessment and at least one follow-up visit. Three different variables (i.e., treatment response) were considered: pharmacological resolution of VMA by Day 28 (VMAres), nonsurgical FTMH closure by Month 6 (MHclos), and combined success when experiencing both events (VMAres + MHclos). First, 
Table 1. Patient demographics and ocular baseline characteristics in the four studies and the integrated dataset

\begin{tabular}{|c|c|c|c|c|}
\hline Characteristic & MIVI-TRUST*(N = 106) & OASIS $(N=50)$ & ORBIT(N = 118) & Integrated $(N=274)$ \\
\hline \multicolumn{5}{|l|}{ Age (years) } \\
\hline Mean (SD) & $68.7(7.4)$ & $66.5(6.3)$ & $66.7(7.3)$ & $67.5(7.2)$ \\
\hline Median & 69.0 & 65.5 & 66.0 & 67.0 \\
\hline Min, Max & 48,85 & 49,79 & 45,88 & 45,88 \\
\hline \multicolumn{5}{|l|}{ Age group (years), $n(\%)$} \\
\hline$<65$ years & $31(29.2)$ & $20(40.0)$ & $42(35.6)$ & 93 (33.9) \\
\hline$\geq 65$ years & $75(70.8)$ & $30(60.0)$ & $76(64.4)$ & $181(66.1)$ \\
\hline \multicolumn{5}{|l|}{ Sex, $n(\%)$} \\
\hline Male & $22(20.8)$ & $10(20.0)$ & $28(23.7)$ & $60(21.9)$ \\
\hline Female & $84(79.2)$ & $40(80.0)$ & 90 (76.3) & $214(78.1)$ \\
\hline \multicolumn{5}{|l|}{ Race, $n(\%)$} \\
\hline White & 99 (93.4) & $46(92.0)$ & $105(89.0)$ & $250(91.3)$ \\
\hline Black or African American & $3(2.8)$ & $4(8.0)$ & $9(7.6)$ & $16(5.8)$ \\
\hline Asian & $2(1.9)$ & $0(0)$ & $3(2.5)$ & $5(1.8)$ \\
\hline Other & $2(1.9)$ & $0(0)$ & $1(0.9)$ & $3(1.1)$ \\
\hline \multicolumn{5}{|l|}{ Lens status, $n(\%)$} \\
\hline Phakic & $81(76.4)$ & $43(86.0)$ & $93(78.8)$ & $217(79.2)$ \\
\hline Pseudophakic & $25(23.6)$ & 7 (14.0) & $24(20.3)$ & $56(20.4)$ \\
\hline Aphakic & $0(0)$ & $0(0)$ & $1(0.9)$ & $1(0.4)$ \\
\hline \multicolumn{5}{|l|}{ ERM status, $n(\%)$} \\
\hline Present & $18(17.0)$ & $6(12.0)$ & $14(11.9)$ & 38 (13.9) \\
\hline Absent & 82 (77.3) & 44 (88.0) & $104(88.1)$ & $230(83.9)$ \\
\hline Missing & $6(5.7)$ & $0(0)$ & $0(0)$ & $6(2.2)$ \\
\hline \multicolumn{5}{|l|}{ EZ status, $n(\%)$} \\
\hline Abnormal & $0(0)$ & 49 (98.0) & $116(98.3)$ & $165(60.2)$ \\
\hline Normal & $0(0)$ & $1(2.0)$ & $2(1.7)$ & $3(1.1)$ \\
\hline Missing & $106(100)$ & $0(0)$ & $0(0)$ & $106(38.7)$ \\
\hline \multicolumn{5}{|l|}{ SRF status, $n(\%)$} \\
\hline Present & $77(72.7)$ & 49 (98.0) & $0(0)$ & $126(46.0)$ \\
\hline Absent & $26(24.5)$ & $1(2.0)$ & $118(100)$ & 145 (52.9) \\
\hline Missing & $3(2.8)$ & $0(0)$ & $0(0)$ & $3(1.1)$ \\
\hline \multicolumn{5}{|l|}{ BCVA (ETDRS letters), $n$ (\%) } \\
\hline$<65$ & $89(84.0)$ & $37(74.0)$ & $96(81.4)$ & $222(81.0)$ \\
\hline $65-75$ & 16 (15.1) & $12(24.0)$ & 19 (16.1) & $47(17.2)$ \\
\hline$>75$ & $1(0.9)$ & $1(2.0)$ & $3(2.5)$ & $5(1.8)$ \\
\hline \multicolumn{5}{|l|}{ FTMH size, $n(\%)$} \\
\hline$\leq 250 \mu \mathrm{m}$ & $48(45.3)$ & $23(46.0)$ & 66 (55.9) & $137(50.0)$ \\
\hline$>250-400 \mu \mathrm{m}$ & 38 (35.9) & $17(34.0)$ & $33(28.0)$ & $88(32.1)$ \\
\hline$>400 \mu \mathrm{m}$ & 19 (17.9) & $10(20.0)$ & $19(16.1)$ & 48 (17.5) \\
\hline Missing & $1(0.9)$ & $0(0)$ & $0(0)$ & $1(0.4)$ \\
\hline \multicolumn{5}{|l|}{ VMA diameter, $n$ (\%) } \\
\hline$\leq 1500 \mu \mathrm{m}$ & $90(84.9)$ & $43(86.0)$ & $110(93.2)$ & $243(88.7)$ \\
\hline$>1500 \mu \mathrm{m}$ & $3(2.8)$ & $2(4.0)$ & $1(0.9)$ & $6(2.2)$ \\
\hline Missing & 13 (12.3) & $5(10.0)$ & $7(5.9)$ & $25(9.1)$ \\
\hline \multicolumn{5}{|l|}{ FTMH width at RPE $(\mu \mathrm{m})$} \\
\hline$n$ & 104 & 50 & 0 & 154 \\
\hline Mean (SD) & $647.1(283.8)$ & $634.2(320.8)$ & - & $642.9(295.4)$ \\
\hline Median & 611.0 & 596.0 & - & 611.0 \\
\hline Min, Max & 113,1572 & 164,2120 & - & 113,2120 \\
\hline \multicolumn{5}{|l|}{ FTMH width at RPE, $n$ (\%) } \\
\hline$\leq 600 \mu \mathrm{m}$ & 49 (46.2) & $25(50.0)$ & $0(0)$ & $74(27.0)$ \\
\hline$>600 \mu \mathrm{m}$ & 55 (51.9) & $25(50.0)$ & $0(0)$ & $80(29.2)$ \\
\hline Missing & $2(1.9)$ & $0(0)$ & $118(100)$ & $120(43.8)$ \\
\hline
\end{tabular}

*MIVI-TRUST consisted of two phase 3 clinical trials (NCT00781859 and NCT00798317)

BCVA, best-corrected visual acuity; ERM, epiretinal membrane; ETDRS, Early Treatment Diabetic Retinopathy Study; EZ, ellipsoid zone; FTMH, full-thickness macular hole; RPE, retinal pigment epithelium; SD, standard deviation; SRF, subretinal fluid; VMA, vitreomacular traction 
Table 2. Rates of VMA resolution and FTMH closure in the four studies and the integrated dataset

\begin{tabular}{|c|c|c|c|c|}
\hline & MIVI-TRUST* $n(\%)$ & OASIS n (\%) & ORBIT $n(\%)$ & Integrated $n(\%)$ \\
\hline Number of patients & 106 & 50 & 118 & 274 \\
\hline VMA resolution & $53(50.0)$ & $27(54.0)$ & $74(62.7)$ & $154(56.2)$ \\
\hline FTMH closure & $43(40.6)$ & $15(30.0)$ & $38(32.2)$ & $96(35.0)$ \\
\hline $\begin{array}{l}\text { VMA resolution: Yes } \\
\text { FTMH closure: Yes }\end{array}$ & $24(22.6)$ & $8(16.0)$ & $30(32.2)$ & $62(22.6)$ \\
\hline $\begin{array}{l}\text { VMA resolution: Yes } \\
\text { FTMH closure: No }\end{array}$ & $29(27.4)$ & $19(38.0)$ & 44 (37.3) & $92(33.6)$ \\
\hline $\begin{array}{l}\text { VMA resolution: No } \\
\text { FTMH closure: Yes }\end{array}$ & 19 (17.9) & 7 (14.3) & $8(6.8)$ & $34(12.4)$ \\
\hline $\begin{array}{l}\text { VMA resolution: No } \\
\text { FTMH closure: No }\end{array}$ & $24(22.6)$ & 8 (16.0) & $30(25.4)$ & $86(31.4)$ \\
\hline
\end{tabular}

*MIVI-TRUST consisted of two phase 3 clinical trials (NCT00781859 and NCT00798317)

FTMH, full-thickness macular hole; VMA, vitreomacular adhesion

Table 3. Univariable logistic regression analysis for the effect of patient demographics and ocular baseline characteristics on VMA resolution by Day 28 and FTMH closure by Month 6 in the integrated dataset

\begin{tabular}{|c|c|c|c|c|c|c|c|}
\hline \multirow[b]{2}{*}{ Characteristic } & \multirow[b]{2}{*}{ Status } & \multicolumn{2}{|c|}{ VMA resolution } & \multicolumn{2}{|c|}{ FTMH closure } & \multicolumn{2}{|c|}{ VMA resolution + FTMH closure } \\
\hline & & Success (\%) & $P$-value & Success (\%) & $P$-value & Success (\%) & $\boldsymbol{P}$-value \\
\hline \multirow[t]{2}{*}{ Age } & $<65$ years & 65/93 (69.9) & \multirow{2}{*}{0.0015} & $32 / 93(34.4)$ & \multirow{2}{*}{0.9783} & 22/93 (23.7) & \multirow{2}{*}{0.735} \\
\hline & $\geq 65$ years & $89 / 181(49.2)$ & & $64 / 181(35.4)$ & & 40/181 (22.1) & \\
\hline \multirow[t]{2}{*}{ Lens Status } & Phakic & 130/217 (59.9) & \multirow{2}{*}{0.0129} & 71/217 (32.7) & \multirow{2}{*}{0.1888} & $47 / 217$ (21.7) & \multirow{2}{*}{0.647} \\
\hline & Pseudophakic & $23 / 56(41.1)$ & & 24/56 (42.9) & & $14 / 56(25.0)$ & \\
\hline \multirow[t]{2}{*}{ ERM status } & Present & 12/38 (31.6) & \multirow{2}{*}{0.0028} & 13/38 (34.2) & \multirow{2}{*}{0.7999} & $4 / 38(10.5)$ & \multirow{2}{*}{0.067} \\
\hline & Absent & 137/230 (59.6) & & $81 / 230(35.2)$ & & $56 / 230(24.3)$ & \\
\hline \multirow[t]{2}{*}{ EZ status } & Normal & 1/3 (33.3) & \multirow{2}{*}{0.3667} & $3 / 3(100)$ & \multirow{2}{*}{0.9852} & 1/3 (33.3) & \multirow{2}{*}{0.645} \\
\hline & Abnormal & 100/165 (60.6) & & $50 / 165(30.3)$ & & $37 / 165(22.4)$ & \\
\hline \multirow[t]{2}{*}{ SRF status } & Present & 67/126 (53.2) & \multirow{2}{*}{0.2874} & 48/126 (38.1) & \multirow{2}{*}{0.2327} & $28 / 126(22.2)$ & \multirow{2}{*}{0.124} \\
\hline & Absent & $85 / 145(58.6)$ & & 46/145 (31.7) & & 33/145 (22.8) & \\
\hline \multirow{4}{*}{$\begin{array}{l}\text { BCVA (ETDRS } \\
\text { letters) }\end{array}$} & $<65$ & $127 / 222(57.2)$ & \multirow{4}{*}{0.6215} & $71 / 222(32.0)$ & & 49/222 (22.1) & \multirow{4}{*}{0.645} \\
\hline & & & & & 0.0606 & & \\
\hline & $65-75$ & $25 / 47(53.2)$ & & $22 / 47(46.8)$ & & $13 / 47(27.7)$ & \\
\hline & $>75$ & $2 / 5(40.0)$ & & $3 / 5(60)$ & & $0 / 5(0)$ & \\
\hline \multirow[t]{2}{*}{ VMA diameter } & $\leq 1500 \mu \mathrm{m}$ & 144/243 (59.3) & \multirow{2}{*}{0.7324} & $87 / 243$ (35.8) & \multirow{2}{*}{0.8514} & $56 / 243(23.0)$ & \multirow{2}{*}{0.489} \\
\hline & $>1500 \mu \mathrm{m}$ & $3 / 6(50)$ & & 2/6 (33.3) & & 2/6 (33.3) & \\
\hline \multirow[t]{3}{*}{ FTMH size } & $\leq 250 \mu \mathrm{m}$ & 75/137 (54.7) & \multirow{3}{*}{0.3412} & 67/137 (48.9) & & 41/137 (29.9) & \\
\hline & $>250-400 \mu \mathrm{m}$ & $54 / 88(61.4)$ & & 26/88 (29.6) & $<0.0001$ & 19/88 (21.6) & 0.009 \\
\hline & $>400 \mu \mathrm{m}$ & $24 / 48(50)$ & & $2 / 48(4.2)$ & & $1 / 48(2.2)$ & \\
\hline $\begin{array}{l}\text { FTMH width at } \\
\text { RPE }\end{array}$ & $\leq 600 \mu \mathrm{m}$ & 40/74 (54.1) & 0.5185 & $38 / 74(51.4)$ & 0.0004 & $21 / 74(28.4)$ & 0.015 \\
\hline & $>600 \mu \mathrm{m}$ & $39 / 80$ (48.8) & & 19/80 (23.8) & & $10 / 80(12.5)$ & \\
\hline
\end{tabular}

BCVA, best-corrected visual acuity; ERM, epiretinal membrane; ETDRS, Early Treatment Diabetic Retinopathy Study; EZ, ellipsoid zone; FTMH, full-thickness macular hole; RPE, retinal pigment epithelium; SRF, subretinal fluid; VMA, vitreomacular adhesion 
Table 4. univariable logistic regression analysis for the effect of patient demographics and ocular baseline characteristics on FTMH closure by Month 6 for patients with VMA resolution by Day 28 in the integrated dataset

\begin{tabular}{|c|c|c|c|}
\hline Patient Characteristic & Status & Success (\%) & $P$-value \\
\hline \multirow[t]{2}{*}{ Age } & $<65$ years & 22/65 (33.8) & \multirow{2}{*}{0.177} \\
\hline & $\geq 65$ years & 49/89 (55.1) & \\
\hline \multirow[t]{2}{*}{ Lens Status } & Phakic & 47/130 (36.2) & \multirow{2}{*}{0.027} \\
\hline & Pseudophakic & 14/23 (60.9) & \\
\hline \multirow[t]{2}{*}{ ERM status } & Present & 4/12 (33.3) & \multirow{2}{*}{0.619} \\
\hline & Absent & $56 / 137$ (40.9) & \\
\hline \multirow[t]{2}{*}{ EZ status } & Normal & 1/1 (100.0) & \multirow{2}{*}{0.986} \\
\hline & Abnormal & $37 / 100$ (37.0) & \\
\hline \multirow[t]{2}{*}{ SRF status } & Present & 28/67 (41.8) & \multirow{2}{*}{0.231} \\
\hline & Absent & 33/85 (38.8) & \\
\hline \multirow[t]{3}{*}{ BCVA (ETDRS letters) } & $<65$ & 49/127 (38.6) & \multirow{3}{*}{0.434} \\
\hline & $65-75$ & 13/25 (52.0) & \\
\hline & $>75$ & $2 / 2(100.0)$ & \\
\hline \multirow[t]{2}{*}{ VMA diameter } & $\leq 1500 \mu \mathrm{m}$ & 56/144 (38.9) & \multirow{2}{*}{0.311} \\
\hline & $>1500 \mu \mathrm{m}$ & 2/3 (66.7) & \\
\hline \multirow[t]{3}{*}{ FTMH size } & $\leq 250 \mu \mathrm{m}$ & $41 / 75(54.7)$ & \multirow{3}{*}{0.001} \\
\hline & $>250-400 \mu \mathrm{m}$ & $19 / 54$ (35.2) & \\
\hline & $>400 \mu \mathrm{m}$ & $1 / 24(4.2)$ & \\
\hline \multirow[t]{2}{*}{ FTMH Width at RPE } & $\leq 600 \mu \mathrm{m}$ & $21 / 40(52.5)$ & \multirow[t]{2}{*}{0.012} \\
\hline & $>600 \mu \mathrm{m}$ & 10/39 (25.6) & \\
\hline
\end{tabular}

BCVA, best-corrected visual acuity; ERM, epiretinal membrane; ETDRS, Early Treatment Diabetic Retinopathy Study; EZ, ellipsoid zone; FTMH, full-thickness macular hole; RPE, retinal pigment epithelium; SRF, subretinal fluid; VMA, vitreomacular adhesion

the effect of each patient baseline characteristic on success was evaluated separately in a univariable logistic regression model that also included study as a fixed-effects factor to accommodate for the clustering in the data due to combining data from different studies. Next, all patient baseline characteristics that were significant at the 5\% significance level were included in a multivariable regression analysis to identify independent patient baseline characteristics that were significantly associated with treatment success. Additionally, the same analysis was performed for MHclos for those patients that experienced VMAres.

\section{RESULTS}

\section{Demographics and Baseline Characteristics}

A total of 274 patients were pooled from the MIVITRUST, OASIS, and ORBIT studies on the basis of having both symptomatic VMA and FTMH at baseline and having received a single intravitreal injection of ocriplasmin $125 \mu \mathrm{g}$. Demographics and ocular characteristics are shown in Table 1. Overall, the demographics and ocular characteristics were generally comparable in patients across the three datasets. The mean age of the patients was 67.5 years, with an age range of $45-88$ years. Seventy-nine percent of the patients had phakic lens status. A majority (60.2\%) of patients had EZ status categorized as abnormal, and $46.0 \%$ of patients had SRF present (Table 1).

\section{VMA Resolution}

An average of $56.2 \%$ (154/274) of eligible patients experienced VMA resolution by Day 28 (Table 2). The proportion of patients experiencing VMA resolution by Day 28 in this patient subpopulation 
Supplemental Table 1. Availability of baseline characteristics and outcome measures in the ocriplasmin studies

\begin{tabular}{|c|c|c|c|}
\hline & MIVI-TRUST & OASIS & ORBIT \\
\hline \multicolumn{4}{|l|}{ Outcome measures } \\
\hline $\begin{array}{l}\text { Pharmacological VMA } \\
\text { resolution at Day } 28, \\
\text { post-resolution vitrectomy } \\
\text { considered as a failure }\end{array}$ & Yes & Yes & No \\
\hline $\begin{array}{l}\text { Pharmacological VMA } \\
\text { resolution at Day } 28, \\
\text { post-resolution vitrectomy } \\
\text { not considered as a failure }\end{array}$ & Yes & Yes & Yes \\
\hline $\begin{array}{l}\text { Non-surgical FTMH closure } \\
\text { by end of study } \\
\text { (post-closure vitrectomy } \\
\text { not considered as a failure) }\end{array}$ & EOS (up to M6) & M6 EOS (up to M24) & M6 M12 \\
\hline \multicolumn{4}{|l|}{ Baseline characteristics } \\
\hline Age (Years) & Available & Available & Available \\
\hline Lens status & $\begin{array}{l}\text { Phakic } \\
\text { Pseudophakic }\end{array}$ & $\begin{array}{l}\text { Phakic } \\
\text { Pseudophakic }\end{array}$ & $\begin{array}{l}\text { Phakic Pseudophakic } \\
\text { Aphakic }\end{array}$ \\
\hline ERM & $\begin{array}{l}\text { Present } \\
\text { Absent }\end{array}$ & $\begin{array}{l}\text { Present Minimal } \\
\text { Present Significant } \\
\text { Absent }\end{array}$ & $\begin{array}{l}\text { Present* } \\
\text { Absent* }\end{array}$ \\
\hline$E Z$ & Not available & $\begin{array}{l}\text { Definitely Fully Intact } \\
\text { Likely site(s) of Incomplete EZ } \\
\text { Definite site(s) of Incomplete EZ } \\
\text { Unable to grade }\end{array}$ & $\begin{array}{l}\text { Normal* } \\
\text { Abnormal* }\end{array}$ \\
\hline SRF & $\begin{array}{l}\text { Present } \\
\text { Absent }\end{array}$ & $\begin{array}{l}\text { Present } \\
\text { Absent }\end{array}$ & $\begin{array}{l}\text { Present* } \\
\text { Absent* }\end{array}$ \\
\hline BCVA (ETDRS) & Available & Available & $\begin{array}{l}\text { Available after } \\
\text { transformation }\end{array}$ \\
\hline FTMH size $(\mu \mathrm{m})$ & Available & Available & Available \\
\hline VMA diameter & Available & Available & Available \\
\hline FTMH width at RPE & Available & Available & Not available \\
\hline
\end{tabular}

${ }^{*}$ Assessed by SD-OCT

BCVA, best-corrected visual acuity; ELM, external limiting membrane; EOS, end of study; ERM, epiretinal membrane; ETDRS, Early Treatment Diabetic Retinopathy Study; EZ, ellipsoid zone; FTMH, full-thickness macular hole; M, month; RPE, retinal pigment epithelium; SD-OCT, spectral-domain optical coherence tomography; SRF, subretinal fluid; VMA, vitreomacular adhesion

with FTMH at baseline was consistently higher than or equal to $50 \%$ for all studies (Table 2).

VMA resolution by Day 28 was achieved significantly more frequently in younger patients, in the absence of ERM at baseline and for eyes with phakic lens status at baseline (Table 3). In the multivariable model including these three variables, age $(P=0.006)$ and ERM status at baseline $(P=0.010)$ remained significant, but not lens status at baseline $(P=0.179)$.

\section{FTMH Closure}

The average rate of FTMH closure by Month 6 in the integrated dataset was 35.0\% (96/274) (Table 2). Closure rates varied from $30.0 \%$ for the OASIS database and $32.2 \%$ for the ORBIT study 
to $40.6 \%$ for the MIVI-TRUST trials (Table 2). FTMH closure by Month 6 occurred significantly more often with smaller FTMH size and smaller FTMH width at RPE (Table 3). We did not construct the multivariable model as these two variables are highly interrelated: the percentage of patients with FTMH width at RPE $\leq 600 \mu \mathrm{m}$ decreases from $64.8 \%(46 / 71)$ to $45.5 \%(25 / 55)$ and $10.7 \%(3 / 28)$ for the $\leq 250 \mu \mathrm{m},>250-400 \mu \mathrm{m}$, and $>400 \mu \mathrm{m} \mathrm{FTMH}$ size categories, respectively.

VMA resolution by Day 28 was a positive predictor for FTMH closure by Month 6. Patients with VMA resolution by Day 28 had a higher percentage of $\mathrm{MH}$ closure of $40.3 \%$ (62/154) compared to patients without VMA release equal to $28.3 \%(34 / 120)(P=0.028)$. Within the group of patients who had VMA resolution by Day 28 , $\mathrm{MH}$ closure by Month 6 occurred significantly more for eyes with pseudophakic lens status at baseline, with smaller FTMH size and smaller FTMH width at RPE (Table 4). In the multivariable models including lens status with one of the two FTMH measurements at a time, lens status was no longer significant $(P=0.244$ with FTMH size and $P=0.173$ with FTMH width at RPE), nor was the FTMH size $(P=0.057)$, but the FTMH width at RPE remained significant $(P<0.001)$.

\section{VMA Resolution and FTMH Closure}

Overall, $22.6 \%(62 / 274)$ of patients in this analysis experienced both VMA resolution by Day 28 and FTMH closure by Month 6 (Table 2). In contrast, $12.4 \%$ (34/274) experienced FTMH closure by Month 6 without VMA resolution by Day 28; 33.6\% (92/274) experienced VMA resolution by Day 28 without FTMH closure by Month 6; and 31.4\% (86/274) showed neither VMA resolution by Day 28 nor non-surgical FTMH closure by Month 6 (Table 2).

Univariable logistic regression analysis revealed a statistically significant effect for FTMH size at baseline on treatment success $(P=0.009$; Table 3 ), with success increasing from $2.2 \%$ for patients with FTMH size at baseline $>400 \mu \mathrm{m}$ to $21.6 \%$ for patients with FTMH size at baseline between 250 and $400 \mu \mathrm{m}$, and further to $29.9 \%$ for patients with FTMH size at baseline $<250 \mu \mathrm{m}$. Similarly, FTMH width at RPE at baseline had a significant effect on treatment success in the univariable logistic regression analysis $(P=0.015$; Table 3$)$, with treatment success increasing from $12.5 \%$ for patients with FTMH width at baseline $>600$ $\mu \mathrm{m}$ to $28.4 \%$ for patients with FTMH width at baseline $<600 \mu \mathrm{m}$. None of the other patient characteristics previously shown to be predictive for VMA resolution, including younger age, phakic lens status, or absence of ERM, ${ }^{[14,33]}$ showed a statistically significant association with treatment success (Table 3). As the two significant patient baseline characteristics are necessarily highly correlated, and additionally FTMH width at RPE at baseline was unavailable for the OASIS dataset, they were not used jointly in a multivariable logistic regression analysis.

\section{Case studies}

Two patients are herein presented as case studies to exemplify real-world clinical findings with ocriplasmin use in patients with symptomatic VMA and FTMH.

\section{Case 1}

A 71-year-old white woman had initial presentation of blurred central vision for four-six weeks and ghosting of letters while reading in the left eye. Medical and ocular history were noncontributory. Visual acuity was 20/60 at initial visit. SD-OCT revealed VMA with tractional macular hole of 300 $\mu \mathrm{m}$, with no presence of ERM (Figure 1A). The left eye had phakic lens status. The patient opted for ocriplasmin treatment and received the intravitreal injection 18 days after initial visit. Visual acuity was 20/60 pre-injection.

One week following the ocriplasmin injection, VMA resolved and the macular hole closed (Figure 1B). However, there was increased presence of SRF (Figure 1B). Visual acuity remained at 20/50. At seven weeks post-treatment, macular hole remained closed with no evidence of SRF (Figure 1C). Visual acuity improved to $20 / 40$.

\section{Case 2}

A 63-year-old White woman initially presented with symptoms of blurred central vision for two-three months in the left eye. Medical history included essential hypertension. Visual acuity was 20/150 at initial visit. Patient had phakic lens status in the left eye. Upon examination, SD-OCT showed 

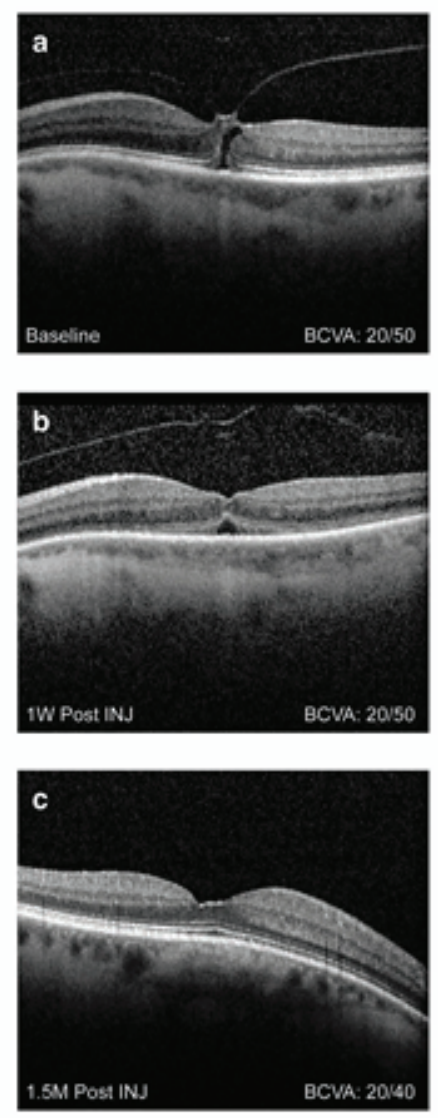

Figure 1. Case 1. Spectral domain optical coherence tomography of a 71-year-old female with VMA and a tractional macular hole in the left eye. (A) Baseline visit. No presence of ERM; BCVA 20/60. (B) One week post ocriplasmin injection. VMA resolved and macular hole closed, but increased presence of SRF; BCVA 20/50. (C). Seven weeks post treatment. Macular hole remains closed, no evidence of SRF; BCVA 20/40. BCVA, best-corrected visual acuity; ERM, epiretinal membrane; INJ, injection; M, month; SRF, subretinal fluid; W, week

FTMH with VMA, with no ERM or presence of SRF (Figure 2A). The size of the tractional macular hole size at baseline was $145 \mu \mathrm{m}$, minimum linear diameter (MLD). The patient opted for ocriplasmin treatment and received the intravitreal injection 14 days after the initial visit. Pre-injection visual acuity was 20/150.

One month following the treatment with ocriplasmin, the VMA released, but the macular hole remained open, enlarging to a size of 428 $\mu \mathrm{m}, \mathrm{MLD}$ (Figure 2B). Visual acuity decreased to 20/200. The patient underwent standard macular hole repair via vitrectomy, internal limiting membrane peeling, and gas injection. The hole did not close and subsequent surgery including an internal limiting membrane patch and silicone oil was performed with macular hole closure. At the last examination, visual acuity was count fingers (CF) at $4 \mathrm{ft}$ with a dense cataract and macular hole closure by OCT.

\section{DISCUSSION}

This study is the first to examine the baseline predictors of success for both VMA resolution and FTMH closure following ocriplasmin treatment. Our results show that $\mathrm{FTMH} \leq 250 \mu \mathrm{m}$ at baseline is significantly associated with VMA release by Day 28 and FTMH closure by Month $6(P=0.009)$, and may be the only positive baseline predictor for both pharmacological VMA release and nonsurgical FTMH closure, including previously identified predictors such as age, lens status, and absence of ERM.

Baseline factors associated with successful VMA release following ocriplasmin treatment have been 

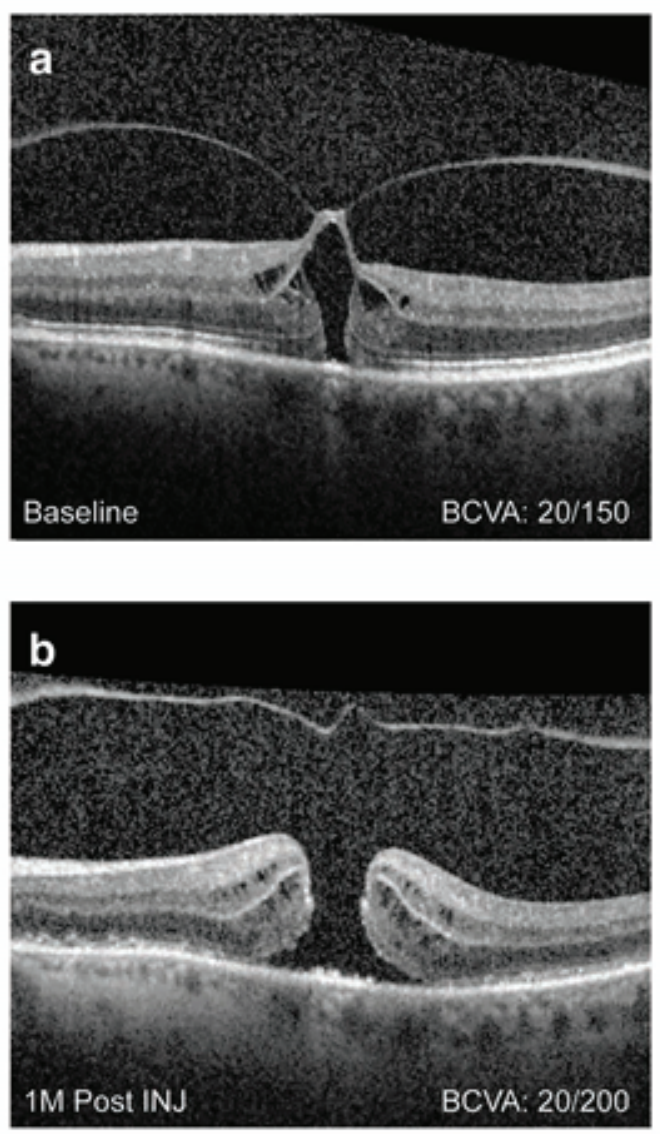

Figure 2. Case 2. Spectral domain optical coherence tomography of a 63-year-old female showing VMA with FTMH. (A) Baseline visit. No ERM or presence of SRF; BCVA 20/150. (B) One month post treatment. VMA released, but macular hole remained open, with the base enlarging to $1323 \mu \mathrm{m}$. BCVA decreased to 20/200. BCVA, best-corrected visual acuity; ERM, epiretinal membrane; INJ, injection; M, month; SRF, subretinal fluid

widely studied following approval in 2012.14-32] A post hoc analysis of the phase 3 MIVI-TRUST trials revealed that baseline characteristics such as younger age, focal adhesions (VMA $\leq 1500 \mu \mathrm{m}$ ), phakic lens status, and absence of ERM promoted VMA resolution, ${ }^{[14]}$ and these characteristics have since been confirmed in multiple studies. ${ }^{[15-32]}$ These predictive characteristics were also shown to statistically favor VMA release (odds ratios 2.377.85 ) in a meta-analysis of 19 studies published in 2016. ${ }^{[33]}$

However, in our current analysis, most of these validated baseline factors were not shown to be predictive when analyzed for both VMA release and FTMH closure. The baseline factors of younger age, absence of ERM, and lens status did not reach statistical significance, with only $\mathrm{FTMH}$ size of $\leq 250 \mu \mathrm{m}$ at baseline emerging as the only statistically significant factor favoring both VMA release and FTMH closure.

The fact that lens status was no longer significant in the multivariable model is due to the correlation between variables. The lens status of younger patients was more frequently phakic compared to older patients (93.6\% vs $71.8 \%)$, and similarly, the lens status of patients without ERM at baseline was more frequently phakic compared to patients with ERM at baseline (83.0\% vs 57.9\%). For FTMH, the percentage of phakic lens status increases with increasing FTMH size, with $80.0 \%$ (60/75), $85.2 \%(46 / 54)$, and $100.0 \%(24 / 24)$ for the $\leq 250$ $\mu \mathrm{m},>250-400 \mu \mathrm{m}$, and $>400 \mu \mathrm{m}$ FTMH size categories, respectively, and with increasing FTMH width, with $85.0 \%$ (34/40) and 89.7\% (35/39) for the $\leq 600 \mu \mathrm{m}$ and $>600 \mu \mathrm{m}$ FTMH width at RPE categories, respectively. 
Historically, whether FTMH at baseline serves as a predictive factor for successful VMA release has remained unclear. The presence of FTMH was initially identified as a predictive characteristic in the post hoc analysis of the MIVI-TRUST trials. $^{[14]}$ Subsequently, Chatziralli et al performed a meta-analysis and did not conclude that the presence of FTMH was a predictive factor for VMA release. ${ }^{[3]}$ However, only 8 of the 19 analyzed studies assessed $\mathrm{MH}$ size as a predictive factor. $^{[13,15,17,23,24,28,30,32]}$ Kuppermann $(2015)^{[39]}$ reported the results of 10 retrospective studies which assessed the presence of FTMH on VMA resolution, including 4 studies not included in Chatziralli et al. ${ }^{[40-43]}$ Eight of these 10 studies $^{[19,23,31,32,40-43]}$ showed that the subgroup of patients with a FTMH had higher VMA resolution rates than those without. ${ }^{[39]}$ These results were also consistent with the prospective OASIS trial. ${ }^{[34]}$ However, other studies have not shown greater rates of VMA resolution in patients with FTMH at baseline. ${ }^{[28,29]}$ Therefore, the value of FTMH as a predictive factor for VMA resolution needs to be further elucidated.

In our current analysis, the majority of patients failing to achieve both VMA resolution and FTMH closure were due to lack of macular hole closure. Whereas VMA resolution rates were $50 \%$ or higher from all studies in this patient population (i.e., those with symptomatic VMA and FTMH at baseline treated with ocriplasmin with at least one follow-up visit), FTMH closure rates for OASIS and ORBIT studies were lower than that of the original phase 3 MIVI-TRUST trials, albeit higher than the closure rates experienced in the control groups (15.4\% and $10.6 \%$, respectively). These results suggest that the known baseline factors predictive of VMA resolution, which were used as key inclusion criteria for the OASIS study, may be necessary but not sufficient to predict FTMH closure. Nevertheless, consistent with our findings, previous studies investigating FTMH closure rates following ocriplasmin treatment have repeatedly shown FTMH size at baseline to be the most consistent predictive factor, with a greater proportion of patients experiencing hole closure with an FTMH $\leq 250 \mu \mathrm{m}$ compared to those with an FTMH $>250-400 \mu \mathrm{m} \cdot{ }^{[14,36,37,44]}$ In contrast, the natural history of untreated FTMH has revealed that spontaneous closure rates are low, ranging from 3-11\%. ${ }^{[45-49]}$ Although smaller holes have a comparatively better chance of spontaneous closure compared to larger ones, previous studies have shown that the majority of stage 2 macular holes $(<400 \mu \mathrm{m})$ progress to stage 3 and beyond if left untreated. ${ }^{[50-53]}$

Whether VMA resolution is correlated with FTMH closure has also remained unclear. Recently, Feng et al demonstrated that successful VMA resolution was a statistically significant positive predictor for FTMH closure following ocriplasmin treatment $(P=0.042) .{ }^{[37]}$ This is consistent with our findings, which showed that patients with VMA resolution by Day 28 had a significantly higher rate of FTMH closure compared to those without VMA resolution. However, other analyses have not shown an association between VMA resolution and FTMH closure. In one study, $40 \%$ of patients required surgical closure for macular holes despite successful VMA resolution, ${ }^{[54]}$ suggesting that additional factors may impact FTMH closure.

Although our finding that VMA resolution showed a positive correlation with FTMH closure is notable, beyond initial hole size, baseline characteristics predictive of macular hole closure prior to treatment have remained elusive. For instance, our findings are consistent with previous analyses showing that, unlike for VMA resolution, absence of ERM did not significantly impact FTMH closure rates. ${ }^{[35,36]}$ Additional studies have suggested that other factors, such as macular hole architecture, may affect closure. ${ }^{[55,56]}$ Recently, Steel et al found that macular hole "width factor," defined as the base diameter (BD) minus the MLD, was the most predictive factor of macular hole closure; holes having a BD close in size to the MLD were shown to have higher probability of closure compared to those with a wider base. ${ }^{[56]}$ A similar outcome is shown in Case 2, where despite VMA resolution, the macular hole widens at the base with the edge elevated by a cuff of SRF. This is consistent with previous cases showing failure of FTMH closure due to base enlargement following ocriplasmin treatment and subsequent VMA resolution. ${ }^{[37,57]}$ SRF did not have a statistically significant predictive value in our analysis; however, the number of patients showing successful VMA resolution and FTMH closure with SRF were strikingly different between the MIVI-TRUST and OASIS vs ORBIT studies (SRF present: $87 \%$ [20/23], 100\% [8/8], and 0\% [0/30], respectively), perhaps owing in part to differences in SRF measurement protocols at study enrollment 
and therefore limiting interpretation. In Case 1, presence of SRF did not impact VMA resolution or FTMH closure, although visual acuity improved following SRF resolution.

When selecting a treatment option for patients with VMA and FTMH, the risks and benefits of ocriplasmin versus vitrectomy should be carefully considered. For these patients, vitrectomy is considered the standard of care, with macular hole closure rates reported for $87.5 \%$ of patients in a meta-analysis. ${ }^{[33,58,59]}$ However, persistence of a macular hole after vitrectomy remains one of the major complications of this type of surgery, with approximately one in eight macular holes failing to close. ${ }^{[58]}$ A persistent macular hole typically increases in diameter, with an accompanying loss of visual acuity, and studies have shown lower treatment success for subsequent surgery. ${ }^{[55,58]}$ Additional complications of vitrectomy include cataract formation, retinal detachment, and hemorrhage. ${ }^{[33,59-64]}$ In addition, based on the OASIS trial, patients who underwent vitrectomy experienced retinal tear and retinal detachment more often than patients receiving ocriplasmin. Most adverse events in the ocriplasmin group were transient in nature, had a short onset time, and were mild to moderate in severity. ${ }^{[34]}$

Strengths of the current analysis include a robust and homogeneous patient sample pooled from multiple clinical trials, utilizing the same ocriplasmin treatment regimen. Limitations include the post hoc nature of the analysis, which was not prespecified in the clinical trials, as well as the lack of availability of certain baseline ocular characteristics in all trials.

Since the pivotal clinical trials, continued study and analysis has been undertaken to more fully understand the efficacy and safety of ocriplasmin, including the baseline characteristics predictive of VMA resolution and FTMH closure. These results suggest that patients presenting with symptomatic VMA and FTMH $\leq 250 \mu \mathrm{m}$ may be ideal candidates for ocriplasmin treatment.

\section{Acknowledgements}

The authors are thankful to all personnel involved in this study and Michael Howell, PhD, for editorial assistance in the preparation of this manuscript that was supported by Oxurion.

\section{Financial Support and Sponsorship}

This study was funded by Oxurion. All authors, including those affiliated with the study sponsor, were involved in the design of the study, interpretation of the data, writing of the manuscript, and the decision to submit the manuscript for publication.

\section{Conflicts of Interest}

The authors declare the following potential conflicts of interest with respect to the research, authorship, and/or publication of this article:

BJ: Consultant for Oxurion; PW: Consultant for Oxurion; TR: Employee of Oxurion; LD: Consultant for Oxurion; JM: Consultant for Oxurion.

Research involving human participants and informed consent

This manuscript represents a retrospective analysis of four prospective phase $3 / 4$ clinical trials.

Full details of adherence to ethics practices have been previously published ${ }^{[13,34,38]}$.

\section{Author Contribution}

All authors contributed to the conception or design of the work, analysis and interpretation of the data, critical revision of the manuscript, and approval of the final version to be published.

\section{REFERENCES}

1. Johnson MW. Perifoveal vitreous detachment and its macular complications. Trans Am Ophthalmol Soc 2005;103:537-567.

2. Sebag J. Vitreous: the resplendent enigma. $\mathrm{Br} J$ Ophthalmol 2009;93:989-991.

3. Garcia-Layana A, Garcia-Arumi J, Ruiz-Moreno JM, AriasBarquet L, Cabrera-Lopez F, Figueroa MS. A review of current management of vitreomacular traction and macular hole. J Ophthalmol 2015;2015:809640.

4. Stalmans P, Duker JS, Kaiser PK, Heier JS, Dugel PU, Gandorfer A, et al. Oct-based interpretation of the vitreomacular interface and indications for pharmacologic vitreolysis. Retina 2013;33:2003-2011.

5. Steel DH, Lotery AJ. Idiopathic vitreomacular traction and macular hole: a comprehensive review of pathophysiology, diagnosis, and treatment. Eye 2013;27:S1-S21.

6. Chang LK, Fine HF, Spaide RF, Koizumi H, Grossniklaus HE. Ultrastructural correlation of spectral-domain optical coherence tomographic findings in vitreomacular traction syndrome. Am J Ophthalmol 2008;146:121-127. 
7. Witkin AJ, Ko TH, Fujimoto JG, Schuman JS, Reichel E, Duker JS. Vitreofoveal attachment causing metamorphopsia: an ultrahigh-resolution optical coherence tomography finding. Retina 2006;26:10851087.

8. John VJ, Flynn HW Jr, Smiddy WE, Carver A, Leonard $\mathrm{R}$, Tabandeh $\mathrm{H}$, et al. Clinical course of vitreomacular adhesion managed by initial observation. Retina 2014;34:442-446.

9. Shao L, Wei W. Vitreomacular traction syndrome. Chin Med J 2014;127:1566-1571.

10. Wittich W, Overbury O, Kapusta MA, Watanabe DH, Faubert J. Macular hole: perceptual filling-in across central scotomas. Vis Res 2006;46:4064-4070.

11. Hong-Kee N, Azhany $\mathrm{Y}$, Lieh-Bin O. Full thickness macular hole: early intervention is an important factor in visual prognosis. Malays Fam Physician 2014;9:42-48.

12. De Giacinto C, Pastore MR, Cirigliano G, Tognetto D. Macular hole in myopic eyes: a narrative review of the current surgical techniques. J Ophthalmol 2019;2019:3230695.

13. Stalmans P, Benz MS, Gandorfer A, Kampik A, Girach A, Pakola S, et al. Enzymatic vitreolysis with ocriplasmin for vitreomacular traction and macular holes. $N$ Engl J Med 2012;367:606-615.

14. Haller JA, Stalmans P, Benz MS, Gandorfer A, Pakola SJ, Girach A, et al. Efficacy of intravitreal ocriplasmin for treatment of vitreomacular adhesion: subgroup analyses from two randomized trials. Ophthalmology 2015;122:117122.

15. Chatziralli I, Theodossiadis G, Parikakis E, Datseris I, Theodossiadis P. Real-life experience after intravitreal ocriplasmin for vitreomacular traction and macular hole: a spectral-domain optical coherence tomography prospective study. Graefes Arch Clin Exp Ophthalmol 2016;254:223-233.

16. Chin EK, Almeida DR, Sohn EH, Boldt HC, Mahajan VB, Gehrs KM, et al. Incomplete vitreomacular traction release using intravitreal ocriplasmin. Case Rep Ophthalmol 2014;5:455-462.

17. Hager A, Seibel I, Riechardt A, Rehak M, Joussen AM. Does ocriplasmin affect the RPE-photoreceptor adhesion in macular holes? Br J Ophthalmol 2015;99:635-638.

18. Itoh Y, Kaiser PK, Singh RP, Srivastava SK, Ehlers JP. Assessment of retinal alterations after intravitreal ocriplasmin with spectral-domain optical coherence tomography. Ophthalmology 2014;121:25062507.e2502.

19. Kim BT, Schwartz SG, Smiddy WE, Doshi RR, Kovach JL, Berrocal AM, et al. Initial outcomes following intravitreal ocriplasmin for treatment of symptomatic vitreomacular adhesion. Ophthalmic Surg Lasers Imaging Retina 2013;44:334-343.

20. Knudsen VM, Kozak I. A retrospective study of a single practice use of ocriplasmin in the treatment of vitreomacular traction. Saudi J Ophthalmol 2014;28:139144.

21. Lommatzsch AP, Gutfleisch M, Dietzel M, Heimes B, Spital $G$, Bohme $M$, et al. [Initial clinical experience in the treatment of vitreomacular traction and macular holes with ocriplasmin]. Klin Monbl Augenheilkd 2014;231:909-914.
22. Maier M, Abraham S, Frank C, Feucht N, Lohmann CP. [Ocriplasmin as a treatment option for symptomatic vitreomacular traction with and without macular hole. First clinical experiences]. Ophthalmologe 2015;112:990-994.

23. Meyer JC, Shah GK, Blinder KJ, Waheed NK, Reichel E, Stalmans $\mathrm{P}$, et al. Early evolution of the vitreomacular interface and clinical efficacy after ocriplasmin injection for symptomatic vitreomacular adhesion. Ophthalmic Surg Lasers Imaging Retina 2015;46:209-216.

24. Miller JB, Kim LA, Wu DM, Vavvas DG, Eliott D, Husain D. Ocriplasmin for treatment of stage 2 macular holes: early clinical results. Ophthalmic Surg Lasers Imaging Retina 2014;45:293-297.

25. Novack RL, Staurenghi G, Girach A, Narendran N, Tolentino M. Safety of intravitreal ocriplasmin for focal vitreomacular adhesion in patients with exudative age-related macular degeneration. Ophthalmology 2015;122:796-802.

26. Quezada-Ruiz C, Pieramici DJ, Nasir M, Rabena M, Steinle $\mathrm{N}$, Castellarin AA, et al. Outer retina reflectivity changes on sd-oct after intravitreal ocriplasmin for vitreomacular traction and macular hole. Retina 2015;35:1144-1150.

27. Reiss B, Smithen L, Mansour S. Transient vision loss after ocriplasmin injection. Retina 2015;35:1107-1110.

28. Sharma P, Juhn A, Houston SK, Fineman M, Chiang $A$, Ho $A$, et al. Efficacy of intravitreal ocriplasmin on vitreomacular traction and full-thickness macular holes. Am J Ophthalmol 2015;159:861-867.e862.

29. Singh RP, Li A, Bedi R, Srivastava S, Sears JE, Ehlers JP, et al. Anatomical and visual outcomes following ocriplasmin treatment for symptomatic vitreomacular traction syndrome. Br J Ophthalmol 2014;98:356-360.

30. Steel DH, Sandinha MT, White K. The plane of vitreoretinal separation and results of vitrectomy surgery in patients given ocriplasmin for idiopathic macular hole. Invest Ophthalmol Vis Sci 2015;56:4038-4044.

31. Warrow DJ, Lai MM, Patel A, Raevis J, Berinstein DM. Treatment outcomes and spectral-domain optical coherence tomography findings of eyes with symptomatic vitreomacular adhesion treated with intravitreal ocriplasmin. Am J Ophthalmol 2015;159:20-30.e21.

32. Willekens K, Abegao Pinto L, Vandewalle E, Stalmans I, Stalmans P. Improved efficacy of ocriplasmin for vitreomacular traction release and transient changes in optic disk morphology. Retina 2015;35:1135-1143.

33. Chatziralli I, Theodossiadis G, Xanthopoulou P, Miligkos M, Sivaprasad S, Theodossiadis P. Ocriplasmin use for vitreomacular traction and macular hole: a meta-analysis and comprehensive review on predictive factors for vitreous release and potential complications. Graefes Arch Clin Exp Ophthalmol 2016;254:1247-1256.

34. Dugel PU, Tolentino M, Feiner L, Kozma P, Leroy A. Results of the 2-year ocriplasmin for treatment for symptomatic vitreomacular adhesion including macular hole (OASIS) randomized trial. Ophthalmology 2016;123:2232-2247.

35. Khan MA, Haller JA. Ocriplasmin for treatment of vitreomacular traction: an update. Ophthalmol Ther 2016;5:147-159.

36. Dugel PU, Regillo C, Eliott D. Characterization of anatomic and visual function outcomes in patients with fullthickness macular hole in ocriplasmin phase 3 trials. Am J Ophthalmol 2015;160:94-99.e91. 
37. Feng $\mathrm{HL}$, Roth $\mathrm{DB}$, Hasan A, Fine HF, Wheatley HM, Prenner JL, et al. Intravitreal ocriplasmin in clinical practice: predictors of success, visual outcomes, and complications. Retina 2018;38:128-136.

38. Khanani AM, Duker JS, Heier JS, Kaiser PK, Joondeph BC, Kozma P, et al. Ocriplasmin treatment leads to symptomatic vitreomacular adhesion/vitreomacular traction resolution in the real-world setting: the phase IV ORBIT study. Ophthalmol Retina 2018;3:32-41.

39. Kuppermann BD. Ocriplasmin efficacy - an analysis of real-world results from 2013 to 2015. Eur Ophthal Rev 2015;9:141-146.

40. Coskey A, Brown DM, Hooten C, Kao LK, Wykoff CC, Major $\mathrm{JC}$, et al. Ocriplasmin for vitreomacular adhesion (VMA) in the clinical setting: rates of VMA release, development of macular hole, and visual outcomes. The Association for Research in Vision and Ophthalmology (ARVO) Annual Meeting. Orlando, FL.

41. Diaz-Rohena R, Flores-Sanchez B. Ocriplasmin in clinical practice. Pan-American Retina and Vitreous Society (SPRV) Meeting. San Juan, Puerto Rico.

42. Nudleman E, Franklin MS, Ruby AJ, Wolfe JD. Ocriplasmin for vitreomacular adhesion: aftermarket experience and findings. American Society of Retina Specialists (ASRS) Annual Meeting. San Diego, CA.

43. O'Neill BP, Shah AP, Coney JM. Resolution of vitreomacular traction using ocriplasmin (Jetrea) and its potential role in diabetic macular edema. The Association for Research in Vision and Ophthalmology (ARVO) Annual Meeting. Orlando, FL.

44. Haynes RJ, Yorston D, Laidlaw DA, Keller J, Steel DH. Real world outcomes of ocriplasmin use by members of the British and Eire Association of Vitreoretinal Surgeons. Eye 2017;31:107-112.

45. Hikichi T, Akiba J, Trempe CL. Effect of the vitreous on the prognosis of full-thickness idiopathic macular hole. Am J Ophthalmol 1993;116:273-278.

46. Chew EY, Sperduto RD, Hiller R, Nowroozi L, Seigel D, Yanuzzi LA, et al. Clinical course of macular holes: the eye disease case-control study. Arch Ophthalmol 1999;117:242-246.

47. Guyer DR, de Bustros S, Diener-West M, Fine SL. Observations on patients with idiopathic macular holes and cysts. Arch Ophthalmol 1992;110:1264-1268.

48. Ezra E, Gregor ZJ, Morfields Macular Hole Study Group Report No 1. Surgery for idiopathic full-thickness macular hole: two-year results of a randomized clinical trial comparing natural history, vitrectomy, and vitrectomy plus autologous serum: Morfields Macular Hole Study Group RAeport no. 1. Arch Ophthalmol 2004;122:224-236.

49. Freeman WR, Azen SP, Kim JW, el-Haig W, Mishell DR 3rd, Bailey I. Vitrectomy for the treatment of full-thickness stage 3 or 4 macular holes. Results of a multicentered randomized clinical trial. The Vitrectomy for Treatment of Macular Hole Study Group. Arch Ophthalmol 1997;115:1121.
50. Hikichi T, Yoshida A, Akiba J, Trempe CL. Natural outcomes of stage 1, 2, 3, and 4 idiopathic macular holes. Br J Ophthalmol 1995;79:517-520.

51. Hikichi T, Yoshida A, Akiba J, Konno S, Trempe CL. Prognosis of stage 2 macular holes. Am J Ophthalmol 1995;119:571-575.

52. Kim JW, Freeman WR, el-Haig W, Maguire AM, Arevalo JF, Azen SP. Baseline characteristics, natural history, and risk factors to progression in eyes with stage 2 macular holes. Results from a prospective randomized clinical trial. Vitrectomy for Macular Hole Study Group. Ophthalmology 1995;102:1818-1828; discussion 1828-1819.

53. Kim JW, Freeman WR, Azen SP, el-Haig W, Klein DJ, Bailey IL. Prospective randomized trial of vitrectomy or observation for stage 2 macular holes. Vitrectomy for Macular Hole Study Group. Am J Ophthalmol 1996;121:605-614.

54. Roth DB, Feng HL, Modi KK, Fine HF, Wheatley HM. Predictors of success with intravitreal ocriplasmin in the treatment of symptomatic vitreomacular adhesion. Invest Ophthalmol Vis Sci 2014;55:298.

55. Hillenkamp J, Kraus J, Framme C, Jackson TL, Roider J, Gabel VP, et al. Retreatment of full-thickness macular hole: predictive value of optical coherence tomography. $\mathrm{Br} J$ Ophthalmol 2007;91:1445-1449.

56. Steel DH, Parkes C, Papastavrou VT, Avery PJ, El-Ghrably IA, Habib MS, et al. Predicting macular hole closure with ocriplasmin based on spectral domain optical coherence tomography. Eye 2016;30:740-745.

57. Benarous A, Le Mer Y. Long-term results of vitrectomy for macular holes after failure of vitreolysis. Ophthalmologica 2018;240:14-22.

58. Hoerauf $\mathrm{H}$. Predictive values in macular hole repair. $\mathrm{Br} \mathrm{J}$ Ophthalmol 2007;91:1415-1416.

59. Mester $\mathrm{V}$, Kuhn F. Internal limiting membrane removal in the management of full-thickness macular holes. Am J Ophthalmol 2000;129:769-777.

60. Cheng L, Azen SP, El-Bradey MH, Scholz BM, Chaidhawangul S, Toyoguchi $\mathrm{M}$, et al. Duration of vitrectomy and postoperative cataract in the vitrectomy for macular hole study. Am J Ophthalmol 2001;132:881887.

61. Cherfan GM, Michels RG, de Bustros S, Enger C, Glaser BM. Nuclear sclerotic cataract after vitrectomy for idiopathic epiretinal membranes causing macular pucker. Am J Ophthalmol 1991;111:434-438.

62. Melberg NS, Thomas MA. Nuclear sclerotic cataract after vitrectomy in patients younger than 50 years of age. Ophthalmology 1995;102:1466-1471.

63. Thompson JT, Glaser BM, Sjaarda RN, Murphy RP. Progression of nuclear sclerosis and long-term visual results of vitrectomy with transforming growth factor beta2 for macular holes. Am J Ophthalmol 1995;119:48-54.

64. Van Effenterre G, Ameline B, Campinchi F, Quesnot S, Le Mer Y, Haut J. [Is vitrectomy cataractogenic? Study of changes of the crystalline lens after surgery of retinal detachment]. J Fr Ophtalmol 1992;15:449-454. 